\title{
Achieving Balanced Energetics through Cocrystallization
}

\author{
Michael K. Bellas and Adam J. Matzger*
}

\begin{abstract}
Achieving energetic materials with a balanced ratio of oxidant to fuel is a challenge that has been difficult to meet through molecular synthesis. The alternative approach, composite formulation, fails to achieve intimate association of the components to the detriment of performance. Herein, the energetic oxidizer ammonium dinitramide $(A D N)$ is combined with fuel-rich pyrazine-1,4-dioxide via cocrystallization. The result is a material with a balanced oxidant/fuel ratio in which the components maintain intimate association. The material exhibits desirable physical and energetic properties which are much improved over ADN and comparable to contemporary energetics.
\end{abstract}

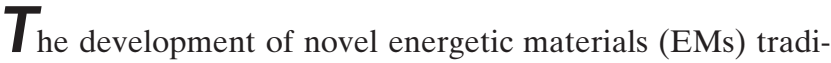
tionally progresses via two pathways: the synthetic combination of fuel (hydrocarbon component) and oxidizing organic functional groups $\left(\mathrm{NO}_{2}, \mathrm{ONO}_{2}\right.$, etc. $)$ on a molecular scaffold, or composite formulation whereby separate oxidizer and fuel components are combined in a physical mixture. ${ }^{[1]}$ The ratio of oxidant to fuel is quantified as oxygen balance $(O B) . O B$ describes the excess $(+)$, or deficiency $(-)$, of oxidant, relative to fuel, in a system, and is the ratio of oxygen present to that required for the complete conversion of the material to neutral gaseous molecules (e.g. $\mathrm{H}_{2} \mathrm{O}, \mathrm{CO}_{2}, \mathrm{CO}$, etc.) expressed as \%. ${ }^{[1]}$ Ideally an EM would be balanced $(O B=0)$ and the oxidizing and fuel components would be in intimate association ensuring optimal detonation/combustion processes. Achieving balanced molecular EMs is rare and the necessarily heterogeneous nature of physical mixtures precludes intimate contact between oxidizing and fuel moieties. Cocrystallization, which is the combination within a crystal lattice of two or more compounds that are solid at ambient in a defined stoichiometry, affords the opportunity to address this need in the field. ${ }^{[2]}$

Although fuel rich EMs are common, there are relatively fewer oxidant-rich molecules to choose from in cocrystal design. Ammonium dinitramide (ADN), $O B=+26 \%$, was selected as the oxidizing coformer because it has demonstrated promise as a replacement for ammonium perchlorate (AP), $O B=+34 \%$, in contemporary composite propellant formulations. ${ }^{[3]} \mathrm{ADN}$ has failed to see wide-spread implementation due to issues with processing, hygroscopicity, and thermal stability ${ }^{[4]}$ As cocrystallization has proved effective at modulating bulk materials properties in various fields includ-

[*] M. K. Bellas, Prof. A. J. Matzger

Department of Chemistry, University of Michigan

930 North University Avenue, Ann Arbor, MI 48109-1055 (USA)

E-mail:matzger@umich.edu

(iD)

Supporting information and the ORCID identification number(s) for the author(s) of this article can be found under https://doi.org/10. 1002/anie.201908709. ing drug delivery, ${ }^{[5]}$ non-linear optics, ${ }^{[6]}$ organic electronics, ${ }^{[7]}$ and $\mathrm{EMs}^{[8]}$ this presents a promising route to balanced EMs while concomitantly redressing ADNs undesirable properties. However, whereas cocrystallization is now widely studied, cocrystallization between neutral and ionic coformers has yet to significantly impact areas outside of pharmaceuticals. ${ }^{[5]}$ This may be due to the difficulties in a priori cocrystal design or the added influence of strong coulombic forces arising from ion-ion interactions. These issues are compounded in EMs by the general lack of supramolecular synthons typically employed in cocrystal design. ${ }^{[9]}$ Few examples exist outside of energetic salt:crown ether complexes $^{[10]}$ and the very recent report of an hexanitrohexaazaisowurtzitane (CL-20):1-amino-3-methyl-1,2,3-triazolium nitrate cocrystal. ${ }^{[11]}$ The lack of progress in this area is indicative of the need to develop new cocrystal design strategies applicable to energetic salt systems.

Developing a design strategy began with identifying those interactions in $\mathrm{ADN}$ that could be perturbed, and therefore exploited, by the introduction of a coformer. In doing so, we identified the ammonium ion $\left(\mathrm{NH}_{4}^{+}\right)$, with its relatively localized charge and hydrogen bond (H-bond) donating ability, as an attractive target. Coformer selection was confined to those compounds bearing strong H-bond accepting functionalities. Among these, $\mathrm{N}$-oxides, displaying formal charge separation, were noted for their lack of basicity (protonated pyridine- $N$-oxide $\left.\mathrm{p} K_{\mathrm{a}}=0.79\right)^{[12]}$ and a search of the Cambridge Structural Database (CSD) revealed two $N$ oxide $: \mathrm{NH}_{4}{ }^{+}$salt cocrystals. ${ }^{[13]}$ These cocrystals both utilize pyridyl- $N$-oxide acceptors, bipyridine dioxide (BPDO) and trans-bis(4-pyridyl)ethylenedioxide (BPED); the use of a bisaccepting coformer represents a second element of our design strategy. A coformer capable of participating in H-bonding interactions with two $\mathrm{NH}_{4}{ }^{+}$could yield a cocrystal with a 2:1 stoichiometry (ADN:coformer) allowing consideration of more fuel-rich coformers. The final design requirement was that the $O B$ of the coformer be complimentary to ADN such that an oxygen-balanced EM may be attained. In discussing $O B$ it is important to note that experimental conditions affect the ratio of product gases; as such, for explosives it is customary to consider all carbon as being converted to $\mathrm{CO}_{2}$ whereas the $O B$ of propellants is often discussed in terms of $\mathrm{CO}$ as this is the favored product under relevant conditions. ${ }^{[14]}$ This final requirement excludes BPDO and BPED from consideration as large, carbon rich backbones would deleteriously affect the $O B$ of any ADN cocrystal. Thus, coformer selection focused on small, strong bis-acceptors. With these design principles in place, pyrazine-1,4-dioxide (PDO) was identified as a potential coformer. There were, however, initial concerns given that PDO is expected to be a weaker $\mathrm{H}$ bond acceptor than either BPDO or BPED. This is evident through comparison of electrostatic potential maps (EPMs) 

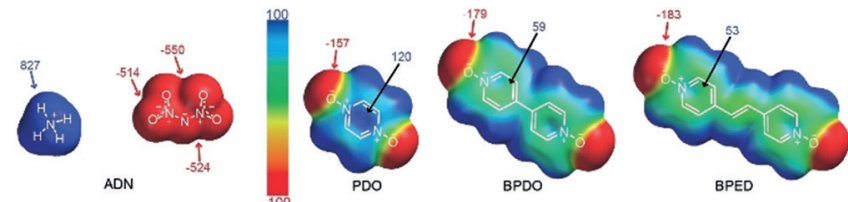

Figure 1. Structures and EPMs of ADN and bis-acceptors. Values given are in $\mathrm{kJ} \mathrm{mol}^{-1}$ and represent local electrostatic minima, $V_{\mathrm{s}, \min }$ (in red), and maxima, $V_{\text {s, max }}$ (in blue); calculated using B3LYP//6-31+G**

for the bis-acceptors (Figure 1). EPMs are visual representations of charge distribution upon an isodensity surface and using EPMs to rank or, in some cases, predict intermolecular interactions in cocrystals is meeting with success for a variety of systems. ${ }^{[15]}$ Beyond the difference in electrostatic potential at the $\mathrm{N}$-oxide functionalities of the bis-acceptors, we also note the significant differences among the electron deficient $\pi$ systems. Despite these differences, PDO proved effective at competing with the dinitramide ion for $\mathrm{H}$-bonding interactions with $\mathrm{NH}_{4}^{+}$and a balanced ADN-PDO cocrystal was obtained.

ADN-PDO is accessible via solution methods or liquid assisted grinding. ADN-PDO is distinguished from the pure coformers by Raman spectroscopy and bulk phase purity was verified using PXRD, which also allowed for the exclusion of false-positives resulting from polymorphism (see SI). ${ }^{[16]}$ The Raman spectra show differences in the signals arising from all modes for both ADN and PDO (see SI). Additionally, the N$\mathrm{H}$ stretch of $\mathrm{NH}_{4}^{+}$shifts from 3163 to $3178 \mathrm{~cm}^{-1}$, suggesting a stronger covalent $\mathrm{N}-\mathrm{H}$ bond in $\mathrm{NH}_{4}^{+}$contained in ADNPDO than in single-component ADN. This change in the covalent bond strength is significant as the first step in the decomposition of ADN is believed to be a proton transfer from $\mathrm{NH}_{4}{ }^{+}$to the dinitramide ion. ${ }^{[4]}$

Single crystal X-ray diffraction of ADN-PDO reveals $0.5 \mathrm{PDO}$ and $1 \mathrm{ADN}$ unit in the asymmetric unit. ADN-PDO exhibits a room temperature (RT) crystallographic density of $1.778 \mathrm{~g} \mathrm{~cm}^{-3}$, compared to 1.808 and $1.597 \mathrm{~g} \mathrm{~cm}^{-3}$ for ADN and PDO, respectively. The RT structure of ADN was determined here as only a low temperature structure is available in the CSD. ${ }^{[17]}$ The packing of the ADN and PDO units involves two unique $\mathrm{H}$-bonding interactions between $\mathrm{N}$ oxide oxygen atoms and $\mathrm{NH}_{4}{ }^{+}$, the shortest of which at an ${ }^{+} \mathrm{N}$ $\mathrm{O}^{-} \cdots \mathrm{NH}_{4}^{+}$contact distance of $2.830 \AA$ (Figure 2). This is comparable to the shortest $\mathrm{NO}_{2} \cdots \mathrm{NH}_{4}{ }^{+}$interaction distance in the crystal structure of ADN at $2.888 \AA$. $\mathrm{NH}_{4}{ }^{+}$also participates in a bifurcated $\mathrm{H}$-bonding interaction with one nitro group of the closest dinitramide ion at $\mathrm{NO}_{2} \cdots \mathrm{NH}_{4}{ }^{+}$distances of 3.110 and $3.007 \AA$. The second nitro group of the dinitramide ion participates in a nitro- $\pi$ interaction at $\mathrm{NO}_{2} \cdots \pi$ (oxygen to centroid) distances of 3.251 and $3.253 \AA$. This establishes the central repeating motif of the structure (blue shaded region, Figure $2 \mathrm{a}$ ). The PDO molecule participates in two nitro- $\pi$ and two ${ }^{+} N-\mathrm{O}^{-} \cdot \ldots \mathrm{NH}_{4}{ }^{+}$interactions (orange shaded region, Figure $2 \mathrm{a}$ ). This arrangement results in a $2 \mathrm{D}$ sheet where each $\mathrm{NH}_{4}{ }^{+}$sits in an oxygen rich pocket (red shaded region, Figure $2 \mathrm{a}$ ). In this pocket, six oxygen atoms are directed towards $\mathrm{NH}_{4}^{+}$which sits only $0.700 \AA$ offcenter (centroid $\cdots \mathrm{NH}_{4}^{+}$) within this cavity- in the direction of
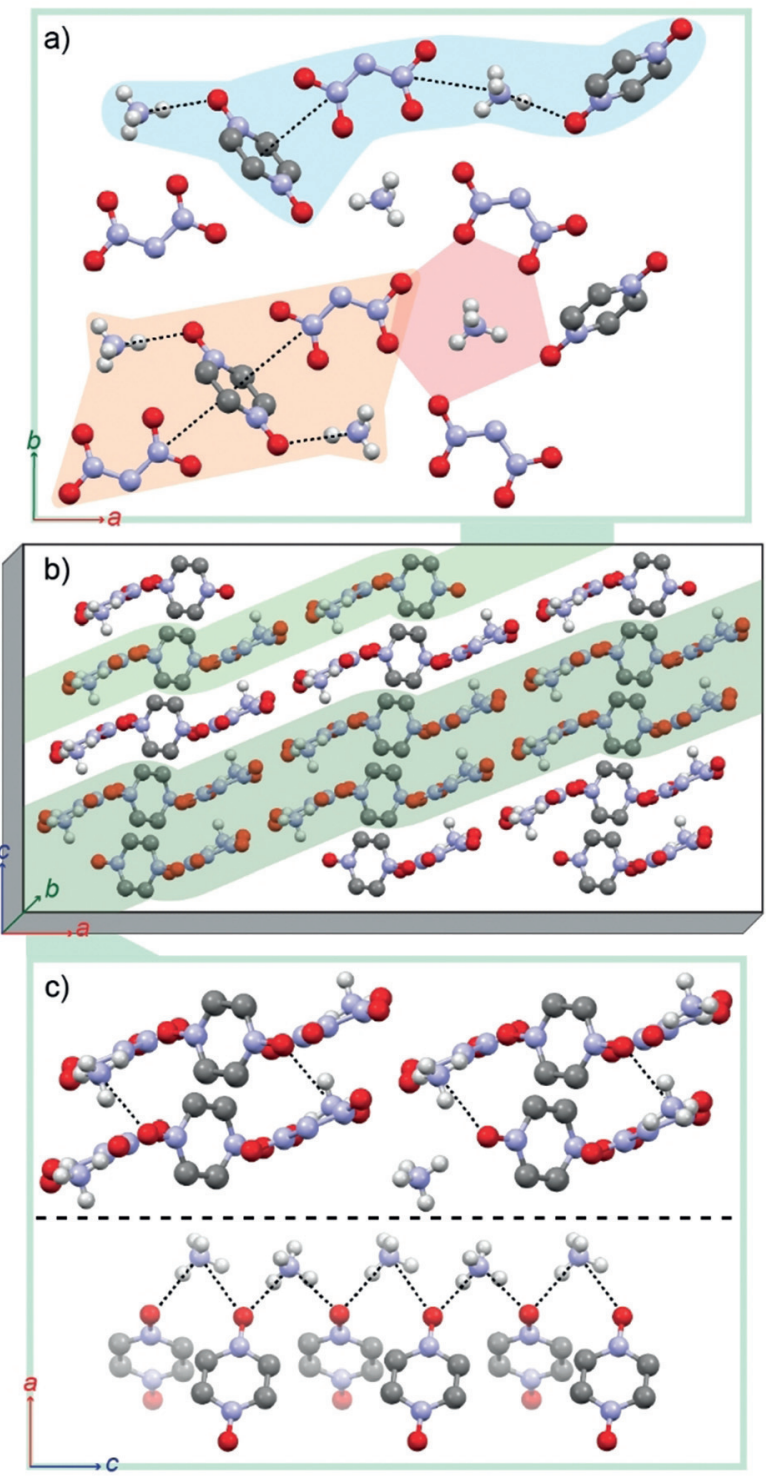

Figure 2. Crystal packing of ADN-PDO. a) intermolecular/ionic interactions in two dimensions (2D), b) stacking of the 2D sheets formed from the interactions displayed in panel $(\mathrm{a}), \mathrm{c}$ ) interactions between 2D sheets.

the ${ }^{+} \mathrm{N}-\mathrm{O}^{-} \ldots \mathrm{NH}_{4}{ }^{+}$interaction. Additionally, $\mathrm{NH}_{4}{ }^{+}$sits $0.292 \AA$ above a mean plane connecting these six oxygen atoms with three hydrogen atoms directed towards this mean plane. The 2D sheets (Figure 2a) stack (Figure 2b,c) via H-bonding interactions between $\mathrm{NH}_{4}{ }^{+}$and $\mathrm{N}$-oxide oxygens in adjacent sheets at an ${ }^{+} \mathrm{N}-\mathrm{O}^{-} \cdot \mathrm{NH}_{4}{ }^{+}$distance of $2.919 \AA$.

As internal order gives rise to external features, cocrystallization results in unique morphology. The morphology of ADN is either needle-like or rod-like, presenting processing challenges which can compromise performance. ${ }^{[18]}$ These issues are commonly addressed by morphology altering processes post-synthesis to produce ADN with an aspect ratio approaching one. ${ }^{[18]}$ The morphology of ADN-PDO (Figure 3) much improved relative to ADN, displaying an aspect ratio closer to unity without additional post-synthesis 


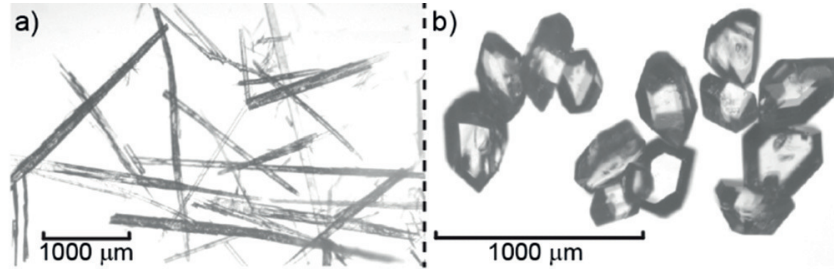

Figure 3. a) Needle-like ADN, b) ADN-PDO crystals.

processing and would lend itself well to dense packing in application.

Thermal stability of EMs is an important consideration, often affecting processing and application. Thermal analysis of ADN-PDO was conducted by differential scanning calorimetry (DSC) and thermogravimetric analysis (TGA) (Figure 4). By DSC, ADN-PDO begins melting at $114^{\circ} \mathrm{C}$ an
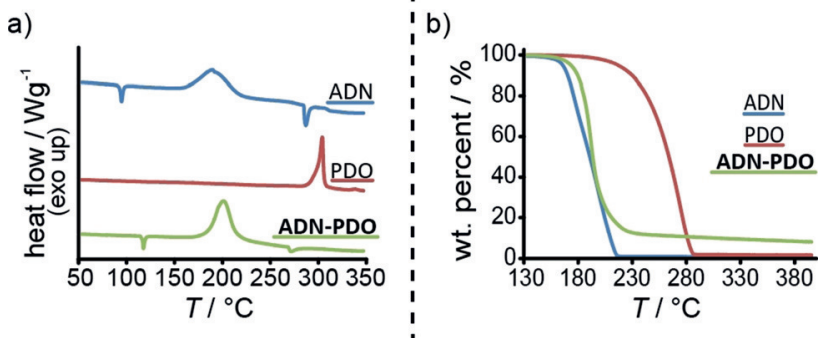

Figure 4. DSC thermograms and TGA traces, a) and b) respectively, for ADN (blue), PDO (red), and ADN-PDO (green).

increase of $>20^{\circ} \mathrm{C}$ relative to $\operatorname{ADN}\left(91.4^{\circ} \mathrm{C}\right)$. With continued heating the decomposition of ADN-PDO commences at $176^{\circ} \mathrm{C}$, a $16^{\circ} \mathrm{C}$ higher value than $\operatorname{ADN}\left(160^{\circ} \mathrm{C}\right)$.

An additional barrier to application of ADN is hygroscopicity. The effect of cocrystallization on the hygroscopicity of ADN was evaluated by determining the critical relative humidity (CRH) for ADN-PDO. The CRH is the minimum relative humidity at which a salt will deliquesce (Figure 5). $\mathrm{ADN}$ has a $\mathrm{CRH}$ of $53.5 \%$ at $25^{\circ} \mathrm{C}$ and is more hygroscopic than AP (see SI). Attempts to address this issue in the past have involved coating ADN in inert polymer binder, or the addition of chemical stabilizers; neither method, however,

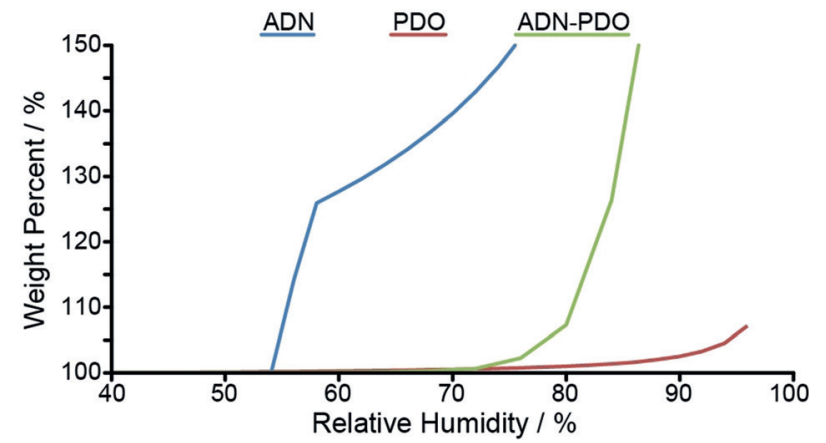

Figure 5. Dynamic vapor sorption traces for ADN (blue), PDO (red), and ADN-PDO (green). addresses the fundamental thermodynamic issue of affinity for water. Cocrystallization directly addresses the affinity of ADN for water by introducing intermolecular/ionic hydrogen bonding interactions to stabilize the material. ADN-PDO exhibits a much improved CRH of $79.5 \%$ at $25^{\circ} \mathrm{C}$.

Our design strategy emphasizes the need to obtain balanced EMs and several criteria are used to describe/ quantify energetic performance. Important considerations for EMs, in general, include detonation velocity $\left(D_{v}\right)$ and detonation pressure $\left(P_{c j}\right)$ while specific impulse $\left(I_{s p}\right)$ is an important metric used in evaluating propellant performance. ADN-PDO is expected to exhibit superior $D_{v}$ and $P_{c j}$, relative to both AP and ADN, and approach that of the high explosives triaminotrinitrobenzene (TATB) and cyclotrimethylenetrinitramine (RDX)—a balanced EM (Table 1). The

Table 1: Energetic performance criteria of contemporary EMs and ADNPDO; values calculated using the thermochemical code CHEETAH.7.0 (see $\mathrm{SI}$ ).

\begin{tabular}{lccccc}
\hline EM & $I_{\mathrm{sp}}[\mathrm{s}]$ & $P_{c j}[\mathrm{GPa}]$ & $D_{\nu}\left[\mathrm{km} \mathrm{s}^{-1}\right]$ & $O B_{(\mathrm{CO})}[\%]$ & $O B_{\left(\mathrm{CO}_{2}\right)}$ \\
\hline AP & 157 & 17.7 & 6.43 & +34 & +34 \\
ADN & 202 & 28.9 & 8.17 & +26 & +26 \\
ADN-PDO & 259 & 33.3 & 8.94 & 0 & -18 \\
TATB & 200 & 34.6 & 8.46 & -19 & -56 \\
RDX & 266 & 35.8 & 8.84 & 0 & -58 \\
\hline
\end{tabular}

$I_{s p}$ of ADN-PDO is dramatically increased $(+27.6 \%)$ relative to ADN, and ADN-PDO based composite propellant systems are comparable to AP based systems used in the space shuttle and Ariane-5 rocket systems as well as similarly oxygen balanced systems based on RDX (see SI). This represents, to our knowledge, a unique synergy achieved by cocrystallizing a positive $O B$ EM with a negative $O B$ coformer.

A design strategy utilizing cocrystallization has been developed and successfully applied to produce an oxygenbalanced EM based on ADN. This affords a synthetic method to achieve oxygen balanced energetic materials which redresses some of the shortcomings of both composite formulation and molecular synthesis approaches while achieving their desirable characteristics. ADN-PDO shows promise as an EM and may find application as an explosive, or in aluminized propellant formulations. Cocrystallization has successfully redressed many of the barriers to the implementation of ADN in energetic systems and ADNPDO represents, to our knowledge, the first ADN cocrystal to accomplish this while preserving performance. This methodology will be applied to the broader class of energetic ammonium salts in efforts to achieve EMs that can act as energetic oxidizers.

\section{Acknowledgements}

Initial support for this work was provided by the Army Research Office via a Multidisciplinary University Research Initiative (grant number: W911NF-13-1-0387); this material is based upon research supported by, or in part by, the U.S. 
Office of Naval Research under award number N00014-19-12086. We thank Ren Wiscons for help with crystal structure determination.

\section{Conflict of interest}

The authors declare no conflict of interest.

Keywords: ammonium dinitramide $\cdot$ cocrystal .

crystal engineering $\cdot$ energetics $\cdot$ noncovalent interactions

How to cite: Angew. Chem. Int. Ed. 2019, 58, 17185-17188 Angew. Chem. 2019, 131, 17345-17348

[1] T. M. Klapötke, Chemistry of High-Energy Materials, 2nd ed. degruyter, Berlin, 2012.

[2] J. Zhang, J. M. Shreeve, CrystEngComm 2016, 18, 6124.

[3] M. B. Talawar, R. Sivabalan, T. Mukundan, H. Muthurajan, A. K. Sikder, B. R. Gandhe, A. Subhananda Rao, J. Hazard. Mater. 2009, 161, 589.

[4] S. Löbbecke, H. H. Krause, A. Pfeil, Propellants Explos. Pyrotech. 1997, 22, 184.

[5] D. J. Berry, J. W. Steed, Adv. Drug Delivery Rev. 2017, 117, 3.

[6] W. Zhu, L. Zhu, L. Sun, Y. Zhen, H. Dong, Z. Wei, W. Hu, Angew. Chem. Int. Ed. 2016, 55, 14023; Angew. Chem. 2016, 128 , 14229.

[7] a) R. A. Wiscons, N. R. Goud, J. T. Damron, A. J. Matzger, Angew. Chem. Int. Ed. 2018, 57, 9044; Angew. Chem. 2018, 130, 9182; b) Y. Huang, Z. Wang, Z. Chen, Q. Zhang, Angew. Chem. Int. Ed. 2019, 58, 9696-9711; Angew. Chem. 2019, 131, $9798-$ 9813.
[8] O. Bolton, A. J. Matzger, Angew. Chem. Int. Ed. 2011, 50, 8960; Angew. Chem. 2011, 123, 9122.

[9] a) G. R. Desiraju, Angew. Chem. Int. Ed. Engl. 1995, 34, 2311; Angew. Chem. 1995, 107, 2541; b) C. B. Aakeröy, A. M. Beatty, B. A. Helfrich, Angew. Chem. Int. Ed. 2001, 40, 3240; Angew. Chem. 2001, 113, 3340.

[10] a) T. Lee, J. W. Chen, H. L. Lee, T. Y. Lin, Y. C. Tsai, S. Cheng, S. Lee, J. Hu, L. Chen, Chem. Eng. J. 2013, 225, 809; b) Y. Wang, Y. Ma, H. Li, Y. Yu, Z. Yang, Chin. J. Energ. Mater. 2018, 26, 545; c) M. Cheng, X. Liu, Q. Luo, X. Duan, C. Pei, CrystEngComm 2016, $18,8487$.

[11] X. Zhang, S. Chen, Y. Wu, S. Jin, X. Wang, Y. Wang, F. Shang, K. Chen, J. Du, Q. Shu, Chem. Commun. 2018, 54, 13268.

[12] H. H. Jaffé, G. O. Doak, J. Am. Chem. Soc. 1955, 77, 4441-4444.

[13] B. Ma, H. Sun, S. Goa, Chem. Commun. 2003, 2164.

[14] M. A. Kettner, T. M. Klapötke in Chemical Rocket Propulsion A Comprehensive Survey of Energetic Materials (Ed.: L. T. DeLuca), Springer, Heidelberg, 2017.

[15] a) D. Musumeci, C. A. Hunter, R. Prohens, S. Scuderi, J. F. McCabe, Chem. Sci. 2011, 2, 883; b) R. V. Kent, R. A. Wiscons, P. Sharon, D. Grinstein, A. A. Frimer, A. J. Matzger, Cryst. Growth Des. 2018, 18, 219.

[16] R. A. Wiscons, A. J. Matzger, Cryst. Growth Des. 2017, 17, 901.

[17] R. Gilardi, J. Flippen-Anderson, C. George, R. J. Butcher, J. Am. Chem. Soc. 1997, 119, 9411.

[18] M. Y. Nagamachi, J. I. S. Oliveira, A. M. Kawamoto, R. C. L. Dutra, J. Aerosp. Technol. Manag. 2009, 1, 153.

Manuscript received: July 12, 2019

Revised manuscript received: September 20, 2019

Accepted manuscript online: September 23, 2019

Version of record online: October 16, 2019 